\title{
Evaluation of Carbon Nanotubes/Polyaniline Thin Films for Development of Electrochemical Sensors
}

\author{
Fabio S. Lisboa, ${ }^{(\circledR \#, a}$ Eduardo G. C. Neiva, ${ }^{\circledR \S, a}$ Marcio F. Bergamini, ${ }^{(1)}$ \\ Luiz H. Marcolino Junior ${ }^{\circledR a}$ and Aldo J. G. Zarbin ${ }^{\circledR} * a$ \\ ${ }^{a}$ Departamento de Química, Universidade Federal do Paraná, CP 19081, 81531-990 Curitiba-PR, Brazil
}

\begin{abstract}
Thin films of multiwalled carbon nanotubes/polyaniline nanocomposites (CNT/PAni) were synthesized through the liquid/liquid (L/L) interfacial route, deposited over glass substrates, and evaluated through cyclic voltammetry and amperometry as electrochemical sensor, using L-ascorbic acid as probe. Films with three different CNT/PAni ratios have been prepared. After the spectroscopic and morphological characterization, the electrochemical sensitivity towards L-ascorbic acid was evaluated and compared with similar sensors prepared from neat multiwalled carbon nanotubes (MWCNT) or neat polyaniline (PAni). The nanocomposite film that presented the best nanotube dispersion through the polymeric matrix presented the higher sensor sensibility, $\left.0.237 \mu \mathrm{A}(\mu \mathrm{mol} \mathrm{L})^{-1}\right)^{-1}$ and a limit of detection (LOD) of $7.91 \mu \mathrm{mol} \mathrm{L} \mathrm{L}^{-1}$. These results evidenced a synergistic effect among the components, and the best response depended on strict control of the polyaniline matrix distribution surrounding the nanotubes.
\end{abstract}

Keywords: carbon nanotubes, polyaniline, nanocomposites, thin films, amperometric sensor

\section{Introduction}

Nanocomposites between carbon nanotubes (CNTs) and conducting polymers, like polyaniline (PAni), are very interesting materials because the individual characteristics of each component can be combined, improved and modified, which allows the compound to be useful in different research fronts. ${ }^{1}$

CNTs present good properties in their different forms, single-walled (that consist in one single tube), double-walled (formed by two concentric tubes) or multiwalled (consisting in many concentric tubes). These properties, as a highly efficient electronic transport and improved mechanical, thermal, and magnetic behavior, ${ }^{2-4}$ are frequently explored in electrochemical sensors construction..$^{5-7}$ Nevertheless, there is a tendency for carbon nanotubes to form a bundle array due to a strong van der Waals inter-tube interaction, which decrease the electronic transport through the carbon nanostructure in comparison with an individual $\mathrm{CNT}^{8}$ When the tubes are closer, a junction resistance occurs because the tube-tube

*e-mail: aldozarbin@ufpr.br

Present adresses: "Instituto de Física e Química, Universidade Federal de Itajubá, CP 50, 37500-903 Itajubá-MG, Brazil; ${ }^{\S}$ Departamento de Química, Universidade Regional de Blumenau, CP 1507, 89030-903 Blumenau-SC, Brazil. contact hinders the electron mobility along the nanotube; as a consequence, the electrical conductivity decreases. ${ }^{9,10}$ This effect can be minimized using a conducting polymer to prepare a nanocomposite, since this kind of material avoids nanotube aggregation and minimizes the high-resistive contact between the tubes. ${ }^{4,11,12}$ Besides, the electronic transport through the composite may be improved by an alignment of the polymer chains and the nanotubes. ${ }^{12}$

Among the several conducting polymers commonly used to prepare carbon nanotubes composites, PAni is broadly applied due to its desirable properties. PAni is a polymer that possesses three different oxidation states: leucoemeraldine, emeraldine base, and pernigraniline, which constitute the totally reduced, the partially reduced, and the total oxidized form, respectively. ${ }^{13}$ Leucoemeraldine and the pernigraniline are practically insulators, but emeraldine base can be modulated by acid doping to form a salt with conducting behavior, the emeraldine salt. ${ }^{14}$ The low cost of the monomer (aniline), the high stability at environmental conditions, the tunable properties, the electrical conductivity (in its emeraldine salt form), the well-established redox processes, and the capacity to form films, make PAni one of the most used conducting polymers in the development of new materials. ${ }^{15-18}$

Since polyaniline presents benzenoid rings on its structure, it is possible for this fragment to interact with 
the CNTs through $\pi-\pi$ interaction..$^{19}$ During the synthesis of the nanocomposite, the initial polymer formation occurs at the wall of the nanotubes, which are coated with the polymer. ${ }^{12,19}$ The carbon nanotubes act like nucleation seeds for the polymer formation, and the interaction results in a synergistic effect between the CNTs and PAni, with enhancement of certain properties in the nanocomposite..$^{1,12,19,20}$

Our research group has developed an innovative way to prepare different carbon nanotubes/polyaniline nanocomposites, directly obtained as thin and transparent films that can be easily deposited over any kind of ordinary substrate, based on an interfacial reaction at a liquid/liquid interface. ${ }^{12,19,20}$ The unique characteristics of these nanocomposites have been explored to different applications, as in photovoltaic devices, ${ }^{19}$ gas sensors, ${ }^{21}$ flexible supercapacitors ${ }^{22}$ and field effect transistor (FET). ${ }^{23}$ In this work, we prepared different thin films of nanocomposites between polyaniline and multi-walled carbon nanotubes (MWCNT) through this liquid/liquid interfacial route, and demonstrated their potential to be used as an electrochemical sensor. L-Ascorbic acid (AA), a very important biomarker, was used as an electrochemical probe, and the results were compared with commercial indium tin oxide (ITO) and both the neat multiwalled carbon nanotube and neat polyaniline films as electrodes. The interest in manufacturing nanocomposites based in CNTs and conducting polymers for electrochemical sensors has increased in recent years, due to their ability to improve sensitivity and electrocatalytic activity of bioanalytical systems. ${ }^{5,24}$ L-Ascorbic acid has been used as a probe in many studies for developing new electrochemical sensors. ${ }^{25}$ The L-ascorbic acid (vitamin C) is a very important antioxidant for human health that acts to prevent diseases as scurvy, and it can be often absorbed by consuming fruits and vegetables. ${ }^{26}$ Due to the well-established electrochemical responses, L-ascorbic acid is a suitable and broadly used probe molecules to verify the potentiality of novel materials in the field of electrochemical sensor.

\section{Experimental}

Multiwalled carbon nanotubes were purchased from Nanocyl-NC7000 (90\% C purity, Sambreville, Belgium); aniline $99.5 \%$ (ACROS, New Jersey, USA) was bi-distillated before use and the other reagents were used without further purification: toluene 99.5\% (Carlo Erba, Milan, Italy), sulfuric acid PA-ACS 95-98\% (Biotec, Khlong Luang, Thailand), ammonium persulfate PA $98.69 \%$ (APS, Neon, Suzano, Brazil), L-ascorbic acid, reagent grade (Sigma-
Aldrich, São Paulo, Brazil), hexacyanoferrate III PA 99\% (Vetec, São Paulo, Brazil) and sodium sulfate $98 \%$ (Vetec, São Paulo, Brazil).

\section{Synthesis of CNT/PAni nanocomposites}

The nanocomposites were synthesized in three different ratios of carbon nanotubes and aniline, CNT:PAni 1:8, $1: 16$, and $1: 32(\mathrm{~m} / \mathrm{m})$. In all procedures the aniline content was maintained constant $(1.5 \mu \mathrm{L})$ and the quantities of carbon nanotube were varied $(0.20,0.10$, and $0.05 \mathrm{mg})$. The thin films were synthesized based on our previous publications ${ }^{12,19}$ by the liquid/liquid interfacial route, using the following conditions: carbon nanotubes were dispersed in $20 \mathrm{~mL}$ of toluene in an ultrasonic bath (Unique USC $1880,154 \mathrm{~W}, 37 \mathrm{~Hz}$ ) for $1 \mathrm{~h}$ at $0{ }^{\circ} \mathrm{C}$. In a $50 \mathrm{~mL}$ round bottom flask, $1.0 \mathrm{mg}$ of APS was dissolved in $20 \mathrm{~mL}$ of $1 \mathrm{~mol} \mathrm{~L}^{-1} \mathrm{H}_{2} \mathrm{SO}_{4}$ aqueous solution under ambient conditions and magnetic stirring at $2500 \mathrm{rpm}$, which was maintained during the whole process. The volume of aniline was added to the carbon nanotube dispersion and after that, this mixture was added to the aqueous phase containing the sulfuric acid and the oxidant. A freestanding green film was observed at the liquid-liquid interface after $3 \mathrm{~h}$ and the reaction was followed by a total time of $22 \mathrm{~h}$.

To remove the oligomers formed during the reaction, the organic phase was exchanged with fresh toluene, using a pipette, for several times until a colorless supernatant was observed, and the aqueous phase was also exchanged with a diluted sulfuric acid aqueous solution until $\mathrm{pH}=3$ was achieved. The films were further deposited over ITO, glass, quartz, or silicon, by pulling the substrate in the direction of the film, according to our previous description. ${ }^{12,19}$ The films deposited over the substrates were dried at $70{ }^{\circ} \mathrm{C}$ for $1 \mathrm{~h}$.

For comparison, samples containing only neat polyaniline or neat CNTs were synthesized using the same methodology for the nanocomposites mentioned above. However, a little change was necessary to form the neat polyaniline film due to the difficulty of forming a good film of only $1.5 \mu \mathrm{L}$ of monomer. Therefore, a volume of $3 \mu \mathrm{L}$ of aniline with the corresponding amount of APS was used.

\section{Electrochemical experiments}

For electrochemical experiments, the films were deposited over ITO substrates with dimensions of $0.5 \times 2.5 \mathrm{~cm}$. A region of the films was cleaned, leaving a covered area of $0.75 \mathrm{~cm}^{2}$ to be immersed in the electrolyte solution. Scan rate studies for each working electrode of thin films and neat ITO were performed using a solution of $1 \mathrm{mmol} \mathrm{L}^{-1}$ potassium hexacyanoferrate prepared in 
aqueous solution of $0.1 \mathrm{~mol} \mathrm{~L}^{-1}$ sodium sulfate/sulfuric acid at $\mathrm{pH}=3$ as electrolyte, and the cyclic voltammograms were collected at $1,4,8,12,16,20,25$ and $30 \mathrm{mV} \mathrm{s}^{-1}$, in a potential window of -0.2 until $0.7 \mathrm{~V}$, to evaluate the electrodes behavior.

L-Ascorbic acid (AA) was employed as electrochemical probe and used in concentration of $1 \mathrm{mmol} \mathrm{L}^{-1}$ prepared in aqueous solution of $0.1 \mathrm{~mol} \mathrm{~L}^{-1}$ sodium sulfate/sulfuric acid at $\mathrm{pH}=3$. Cyclic voltammetry in a potential range of 0.0 to $0.7 \mathrm{~V}$ at scan rate of $25 \mathrm{mV} \mathrm{s}^{-1}$, and amperometric studies in a potential of $0.25 \mathrm{~V}$, both with magnetic stirring at $600 \mathrm{rpm}$, were done to evaluate the current increase at each L-ascorbic acid addition.

In all experiments, the materials employed were subjected to stabilization by cycling the electrodes 20 times in the electrolyte solution used (aqueous solution of $0.1 \mathrm{~mol} \mathrm{~L}^{-1}$ sodium sulfate/sulfuric acid at $\mathrm{pH}=3$ ) at a scan rate of $50 \mathrm{mV} \mathrm{s}^{-1}$.

\section{Physical characterization}

The scanning electron microscope (SEM) images were obtained in a MIRA-3 FEG-SEM Tescan microscope. Raman data were acquired using an excitation line of $632.8 \mathrm{~nm}$ (He-Ne laser) in a Renishaw Raman Image spectrophotometer. UV-Vis spectra were collected in a Shimadzu UV-2450 spectrophotometer, directly from the films deposited over quartz substrates.

The electrochemical experiments were performed using an Autolab PGSTAT-128N potentiostat and NOVA software to collect the data. A three-electrode cell was used with a Pt counter-electrode, an $\mathrm{Ag} / \mathrm{AgCl}$ reference electrode, and the films as working electrodes.

\section{Results and Discussion}

\section{Characterization of CNT/PAni nanocomposites}

The UV-Vis spectra of the nanocomposites showed in Figure 1A presented a typical profile for the emeraldine salt of polyaniline, containing the three foremost absorption bands: at $340 \mathrm{~nm}$ (attributed to the band gap transition) and two others at 440 and $770 \mathrm{~nm}$, involving polaronic/ bipolaronic transitions. It is also possible to observe the absorption band for carbon nanotubes at $270 \mathrm{~nm}$, attributed to the $\pi \rightarrow \pi^{*}$ transition of carbon $\mathrm{sp}^{2}$. As expected, the band around $770 \mathrm{~nm}$ is shifted to higher wavelengths as the carbon nanotubes content in the nanocomposite increased. This means that more extended chains of the polymer are in contact with sidewalls of the carbon nanotubes, as reported before. ${ }^{12}$
The Raman spectra collected at $\lambda=632.8 \mathrm{~nm}$ (Figure 1B), presented the bands for the emeraldine salt form of polyaniline at 1173 and $1585 \mathrm{~cm}^{-1}(\mathrm{C}-\mathrm{H}$ bending and $\mathrm{C}=\mathrm{C}$ stretching of quinoid rings, respectively), $1486 \mathrm{~cm}^{-1}$ ( $\mathrm{C}=\mathrm{N}$ of the quinoid non-protonated di-imine), $1259 \mathrm{~cm}^{-1}$ (C-N stretching in benzene diamine units), $1324 \mathrm{~cm}^{-1}\left(\mathrm{C}-\mathrm{N}^{+}\right.$stretching of the polaronic structure), $1624 \mathrm{~cm}^{-1}$ (C-C stretching of the benzenoid rings), and 880 and $814 \mathrm{~cm}^{-1}$ (out-of-plane $\mathrm{C}-\mathrm{H}$ vibrations of the aromatic rings). The bands related to the carbon nanotubes in the nanocomposites are observed at 1341, 1586, and $2657 \mathrm{~cm}^{-1}$, corresponding to the well-known D, G, and G' bands, respectively. ${ }^{20}$

The SEM images in Figures 1C, 1D, and 1E show the morphology of the films. It is possible to observe the formation of polyaniline around the carbon nanotubes and also to visualize different degrees of dispersion of the carbon nanotubes in the polymeric matrix. In all images, nanotubes capped by the polymer are observed, as expected, considering the nanotubes acting like seeds for polymer growing. ${ }^{1921}$ While it is possible to see an agglomerate of polymeric chain in Figure 1C, and non-totally capped nanotubes in Figure 1E (indicated by white arrows), corresponding to 1:32 and 1:8 composites, a more homogeneous dispersion can be observed in Figure 1D, in which the proportion CNT:aniline equals $1: 16$, indicating a reasonable ratio between carbon nanotube and polyaniline, which provides a CNT totally capped by polymer composites.

Electrochemical characterization and analytical potentiality

Preliminary studies were performed to know the electrochemical behavior of the proposed nanocomposite, in comparison with its components individually. For this, a cyclic voltammetric profile only in supporting electrolyte (solution of $\mathrm{Na}_{2} \mathrm{SO}_{4} / \mathrm{H}_{2} \mathrm{SO}_{4}$ in $\mathrm{pH}=3$ ) for each produced film and ITO (bare electrode) was obtained and the cyclic voltammogram is presented at Figure 2a. Cyclic voltammograms for ITO (black line) and MWCNT (blue line) do not show any redox process at the scan range of 0 to $0.7 \mathrm{~V}$. Films of neat polyaniline (PAni) and the CNT/PAni nanocomposite presented the process of oxidation/ reduction characteristic of polyaniline, attributed to changes of leucoemeraldine to emeraldine salt form and emeraldine salt to pernigraniline. ${ }^{27,28}$ For the electrode prepared with neat PAni (red line), faradaic signals were observed at 0.46 and $0.57 \mathrm{~V}$ for the anodic processes, and at 0.51 and $0.42 \mathrm{~V}$ for the cathodic processes. The nanocomposite (green line) presented the anodic processes at 0.47 and $0.58 \mathrm{~V}$, and cathodic processes at 0.52 and $0.40 \mathrm{~V} .^{27,28}$ 

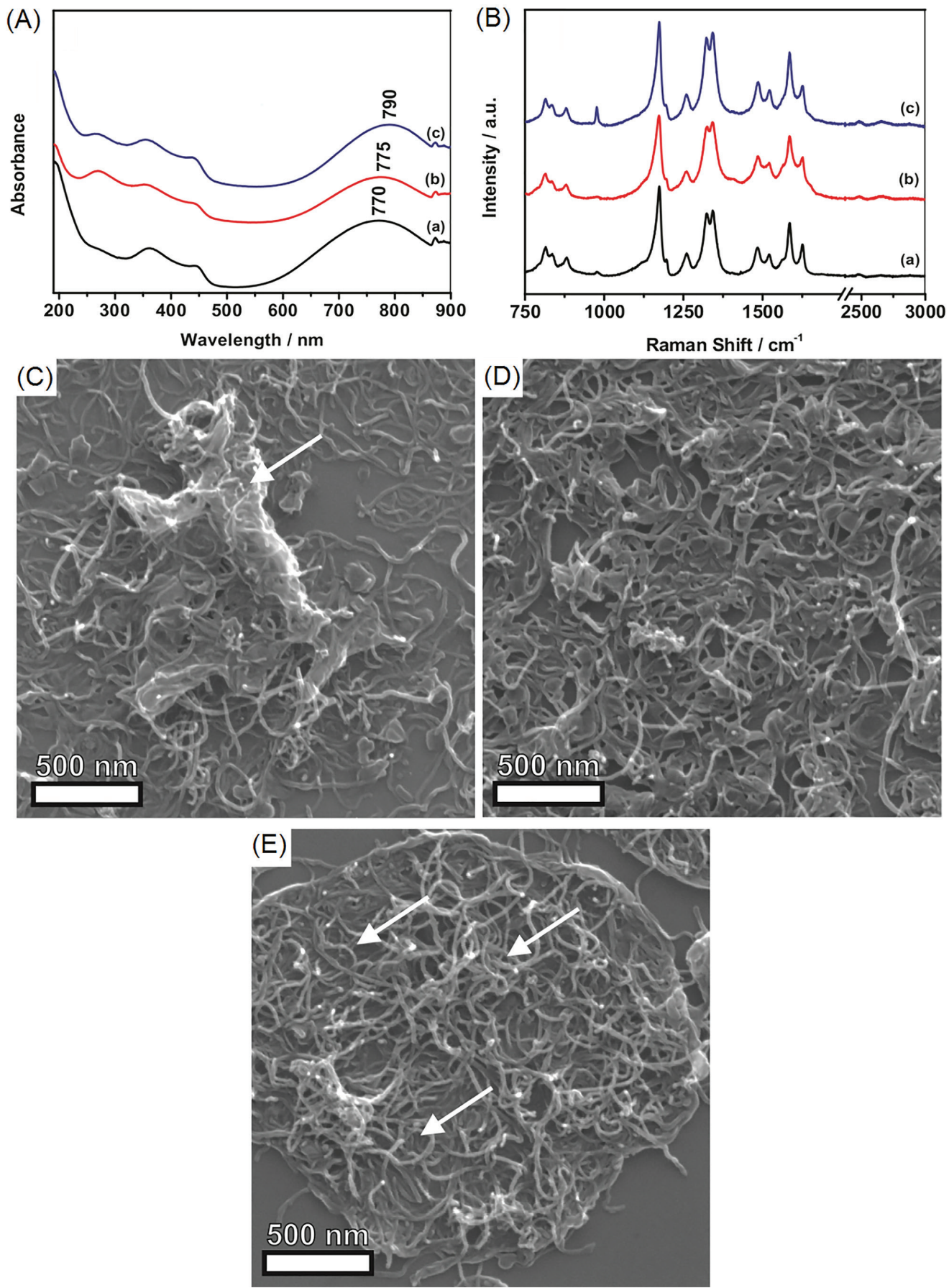

Figure 1. (A) UV-Vis spectra of the CNT/PAni nanocomposites with CNT:aniline ratios of (a) 1:32, (b) 1:16 and (c) 1:8; (B) Raman spectra of CNT/PAni nanocomposites with CNT:aniline ratios of (a) 1:32, (b) 1:16 and (c) 1:8; SEM images of CNT/PAni nanocomposites with CNT:aniline ratios of (C) 1:32; (D) 1:16 and (E) 1:8.

A similar study was performed in the presence of $1.2 \mathrm{mmol} \mathrm{L}^{-1} \mathrm{~L}$-ascorbic acid (AA) and the results are shown at Figure 2b. Except for ITO electrode, the addition of L-ascorbic acid in the electrochemical cell changes the voltammetric profiles of each material with the appearance of a non-reversible faradaic process, attributed to the AA oxidation. In this process, the AA is converted to dehydroascorbic acid (DHAA) releasing two electrons and two protons. ${ }^{29,30}$ As can be seen, the proposed CNT/PAni nanocomposite exhibited a higher electrocatalytic behavior for AA oxidation compared with the others. Although it presented a current increase very similar to the MWCNT film, the anodic peak moves to lower potential, with a gain of $140 \mathrm{mV}$, which means a less energetic process. The best electrocatalytic behavior, evidenced by the current increase for each AA addition presented by the CNT/PAni 

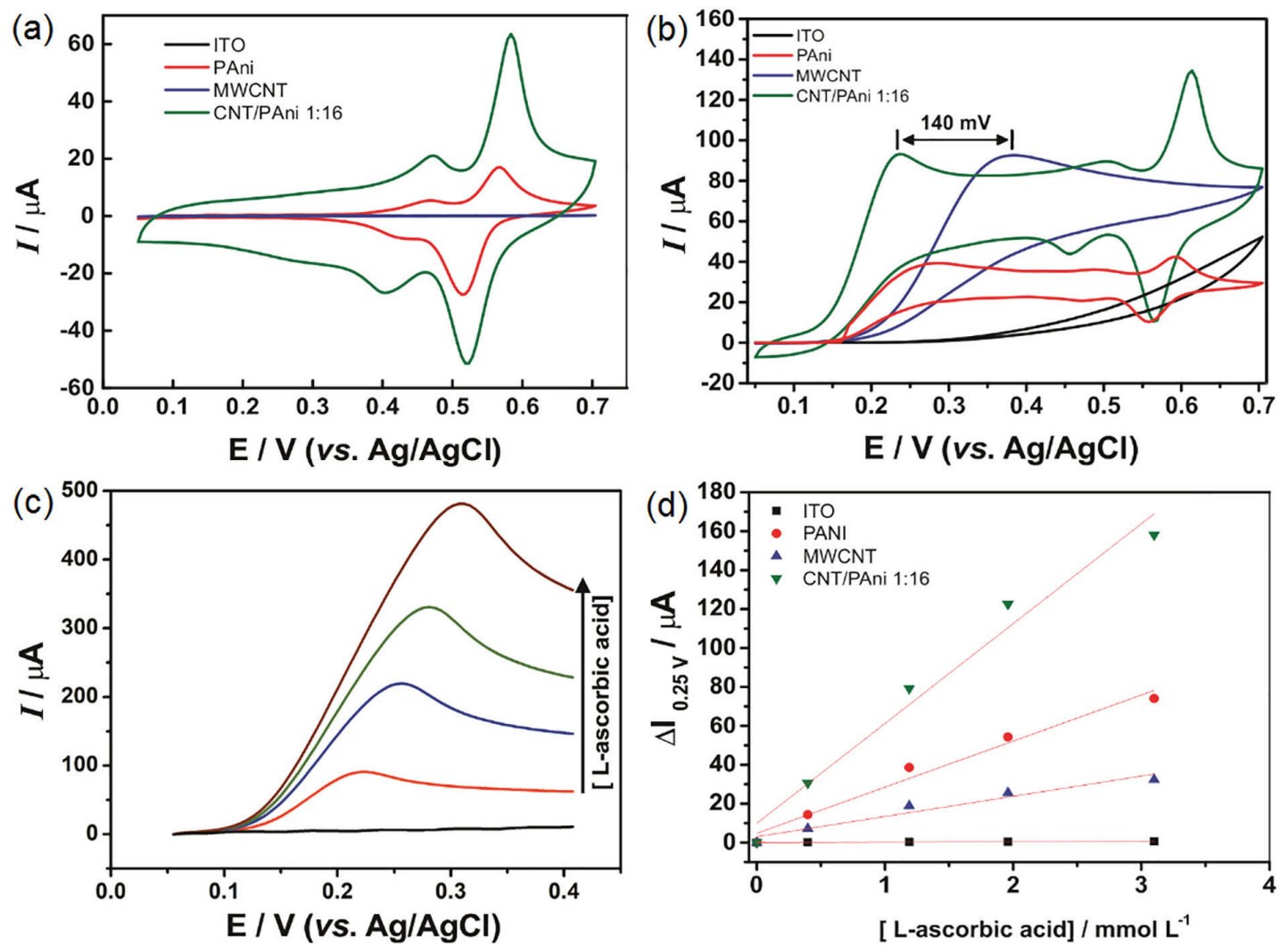

Figure 2. (a) Cyclic voltammograms obtained in a $0.1 \mathrm{~mol} \mathrm{~L}^{-1}$ solution of $\mathrm{Na}_{2} \mathrm{SO}_{4} / \mathrm{H}_{2} \mathrm{SO}_{4}$ in $\mathrm{pH}=3$ at scan rate of $25 \mathrm{mV} \mathrm{s}$, for ITO (black), PAni (red), MWCNT (blue) and the nanocomposite CNT/PAni 1:16 (green). The line of ITO (black) is not seen because it is covered by the MWCNT line in blue; (b) cyclic voltammograms obtained for ITO, PAni, MWCNT and CNT/PAni 1:16, in solution of $0.1 \mathrm{~mol} \mathrm{~L}^{-1} \mathrm{Na}_{2} \mathrm{SO}_{4} / \mathrm{H}_{2} \mathrm{SO}_{4}$ at $\mathrm{pH}=3$, at range of 0.0 to $0.7 \mathrm{~V}$, with addition of aliquots of $1.19 \times 10^{-3} \mathrm{~mol} \mathrm{~L}^{-1}$ of L-ascorbic acid; (c) current increase for each addition $\left(0\right.$ to $\left.1.96 \times 10^{-3} \mathrm{~mol} \mathrm{~L}^{-1}\right)$ of ascorbic acid for nanocomposite CNT/PAni 1:16 electrode; (d) current increase with addition of aliquots of L-ascorbic acid at scan rate of $25 \mathrm{mV} \mathrm{s}^{-1}$ obtained for ITO, PAni, MWCNT and CNT/PAni 1:16 electrodes.

nanocomposite, can be attributed to the synergistic effect between the polymer and the carbon nanotubes, because it can generate an increase of the electroactivity area. ${ }^{30,31}$ The more aligned polymeric structure resulting of the interaction with the carbon nanotubes may improve the mobility of the charge carriers, and the tube-tube resistance junction is minimized when covered by the polyaniline layer in the nanocomposite, which can make easier the electronic transport.

In order to evaluate the sensitivity of the proposed nanocomposite in the AA electro-oxidation, pseudoanalytical curves were obtained for each electrode. Figure $2 \mathrm{c}$ presents the linear sweep voltammograms for the CNT/PAni electrode after addition of AA solution in a concentration range of 0.0 to $1.96 \times 10^{-3} \mathrm{~mol} \mathrm{~L}^{-1}$. The same set of data were obtained for other electrodes (ITO, neat PAni and neat CNTs, Figure S1, Supplementary Information (SI) section). All evaluated electrodes yielded an increase in the anodic current peak with increasing AA concentrations in the electrochemical cell. The linear relationship between analytical signals and AA concentration is presented on Figure 2d. As expected, sensitivity values increased with addition of a new material over ITO electrode, probably caused by an improvement in the device conductivity. Best results (high sensitivity values) were obtained by the proposed CNT/PAni nanocomposite, which presents a sensitivity of $\left.0.208 \mu \mathrm{A}(\mu \mathrm{mol} \mathrm{L})^{-1}\right)^{-1}$, about three and ten times higher than neat PAni and neat CNT electrodes, respectively. Based on the above-mentioned discussion, we can confirm the synergic effect of PAni and CNTs in the nanocomposite for the AA electrooxidation. This property is very desirable in the development of electrochemical sensors and deserves to be further investigated.

\section{Effect of CNT/PAni ratio}

The chronoamperograms obtained at $0.25 \mathrm{~V}$ for each nanocomposite (Figure 3) presented a great variation in current increase response comparing the ratios 1:16, 1:32, and 1:8. The latter had the lowest values of current with addition of L-ascorbic acid, a range of 10.4 to $59.6 \mu \mathrm{A}$, while the others had greater values than that, but presented practically the same current response when compared together, a range of 18.6 to $105.3 \mu \mathrm{A}$. 


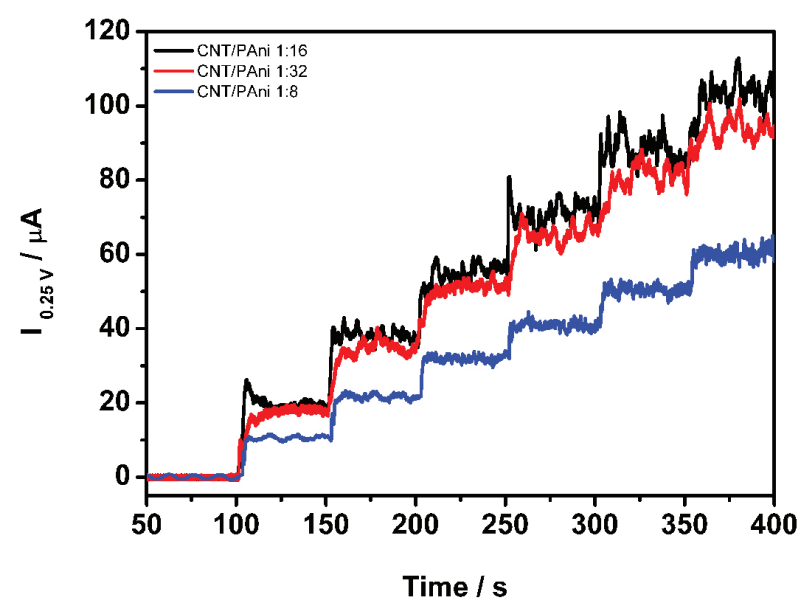

Figure 3. Chronoamperograms obtained for the nanocomposites CNT/PAni in ratios of 1:8 (blue), 1:16 (black) and 1:32 (red) with addition of ascorbic acid using a potential of $0.25 \mathrm{~V}$ in a solution of $0.1 \mathrm{~mol} \mathrm{~L}^{-1}$ $\mathrm{Na}_{2} \mathrm{SO}_{4} / \mathrm{H}_{2} \mathrm{SO}_{4}$ at $\mathrm{pH}=3$.

As the mechanism for L-ascorbic acid oxidation involves electrons and protons transfer to form the L-dehydroascorbic acid, initially by an interaction with the electrode surface,,$^{29,30}$ a good dispersion of the nanotubes in the polymeric matrix can explain the response obtained for the electrodes constructed with different CNT/PAni ratios.

As can be seen in Figure 1E, the proportion 1:8, despite the larger quantities of nanotubes used in the nanocomposite synthesis, presented agglomerates of tubes and a low dispersion of the nanotubes in the PAni matrix, which causes a minor interaction between the carbon nanotubes and the polyaniline in its conducting form. The interaction between agglomerated tubes can make more difficult the electronic processes involved in the ascorbic acid oxidation, probably because the existence of contact resistance between tubes formed in the agglomerated of nanotubes decreases the material's conductivity. Also, the agglomerates can make more difficult the analyte access to the surface of the polymeric layer involved in the electrocatalysis of ascorbic acid oxidation. These two facts may justify the lower current response shown in Figure 3 (blue line). ${ }^{31-33}$

For CNT/PAni 1:16 and CNT/PAni 1:32, it was observed that both presented practically the same current increment (Figure 3, black and red lines). In Figures 1C and $1 \mathrm{D}$, it is possible to see that dispersions of nanotubes in the nanocomposites presented small differences. In Figure 1D, a good dispersion is observable because the polymer uniformly covers the nanotubes, and in Figure 1C, a larger concentration of polymer over the carbon nanotubes covered by polyaniline was observed, which results in a poorer dispersion, but it allows the interaction between the analyte and the polyaniline, and also with accessible nanotubes covered by the polymer.
It was discussed the presence of nanotubes in the polymeric matrix can improve the electrocatalytic response of PAni for L-ascorbic acid determination, but these results show that an excess of nanotubes can reduce the current response, probably because this excess can block the analyte access to the PAni.

\section{Analytical features}

Chronoamperometric measurements were performed at $0.25 \mathrm{~V}$ in order to obtain the sensitivity of each material for L-ascorbic acid determination. At first, the materials were cycled 20 times until their stabilization at a scan rate of $25 \mathrm{mV} \mathrm{s}^{-1}$ in a range of 0.0 to $0.7 \mathrm{~V}$. Figures $4 \mathrm{a}$ and $4 \mathrm{~b}$ present, respectively, the chronoamperograms of each material tested and the current values as a function of the analyte concentration in the cell, obtained from these chronoamperograms.

Based on the good response presented by the nanocomposite CNT/PAni 1:16 as work electrode in L-ascorbic acid determination, an analytical curve was constructed for the concentration range from 0.01 to $0.4 \mathrm{mmol} \mathrm{L}^{-1}$. The data is shown in Figure $4 \mathrm{c}$, and the corresponding analytical curve is showed in Figure 4d.

The analytical curve demonstrated that the electrode presented a linear region with sensitivity at the range of 0.01 to $0.5 \mathrm{mmol} \mathrm{L}^{-1}$ equals to $0.237 \mu \mathrm{A}\left(\mu \mathrm{mol} \mathrm{L}^{-1}\right)^{-1}$. The limit of detection (LOD), calculated using the standard deviation of $0.62 \mu \mathrm{A}$, was $7.91 \mu \mathrm{mol} \mathrm{L} \mathrm{L}^{-1} .{ }^{32}$ When compared to other results found in the literature (Table S1, SI section), values obtained for the nanocomposite developed in this study indicate potentiality for ascorbic acid determination due to the wide linear range of detection and the low LOD exhibited.

\section{Conclusions}

Thin and freestanding films of CNT/PAni composites were obtained in three different CNT/Pani ratios through the interfacial polymerization of aniline, and these composites presented promising results for application as electrochemical sensors. The synthesized composites presented better results when compared to the neat materials and to the conducting substrate, showing a synergistic effect between CNT and PAni. The L-ascorbic acid detection was directly related to the CNT/PAni ratio, indicating that the interaction between CNT and PAni plays an important role in the electrochemical detection. An interesting point to be highlighted here is related to the stability of the synthesized materials towards both ambient atmosphere and redox cycles (as demonstrated before) ${ }^{22}$ which would guarantee 

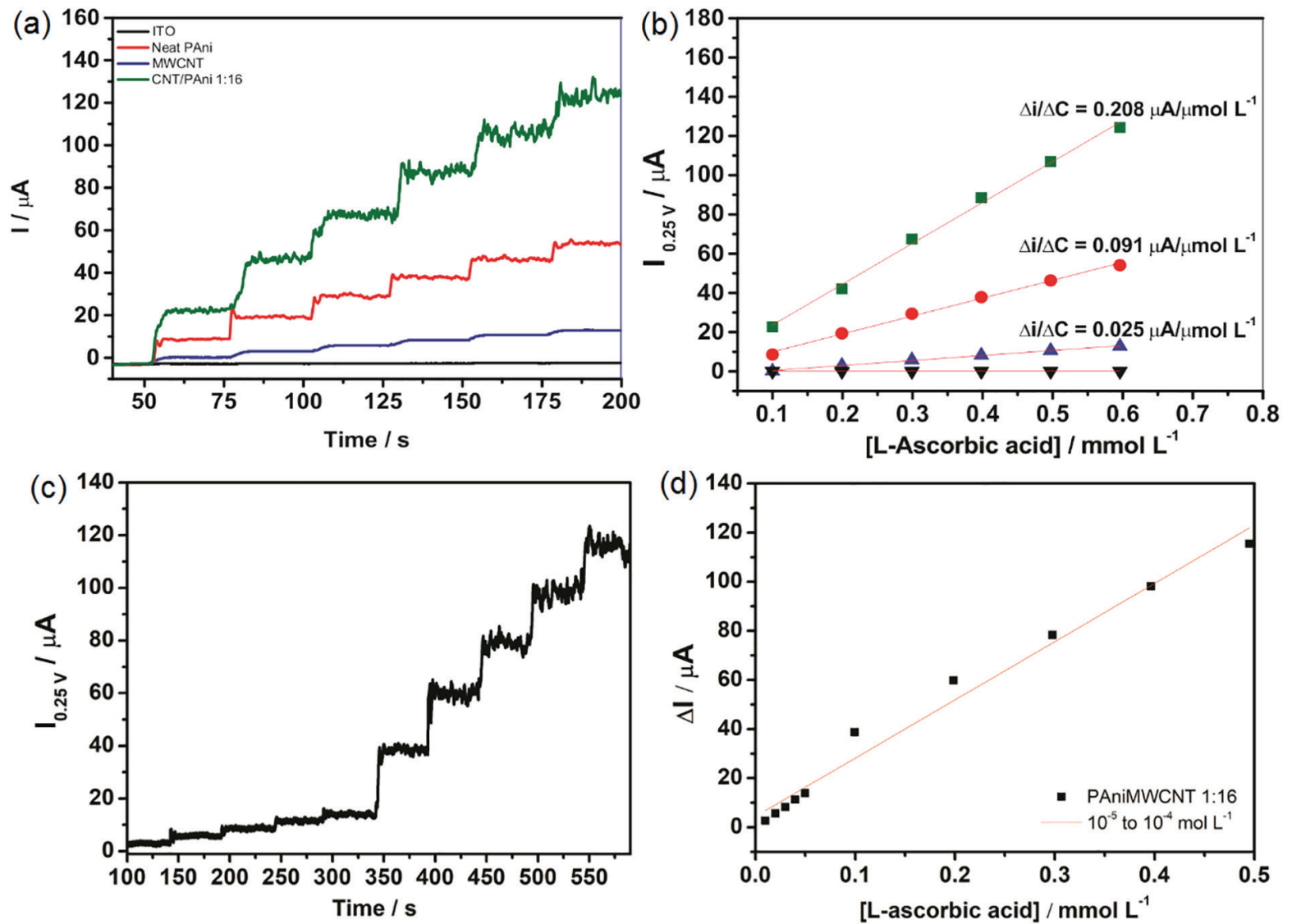

Figure 4. (a) Chronoamperograms of each material tested: ITO (black), PAni (red), MWCNT (blue) and CNT/PAni 1:16 (green); (b) current response increase at $0.25 \mathrm{~V}$ and sensitivity obtained by chronoamperometry for the consecutive analyte additions. All experiments are made in solution of $0.1 \mathrm{~mol} \mathrm{~L}^{-1}$ $\mathrm{Na}_{2} \mathrm{SO}_{4} / \mathrm{H}_{2} \mathrm{SO}_{4}$ at $\mathrm{pH}=3$, at scan rate of $25 \mathrm{mV} \mathrm{s}{ }^{-1}$; (c) chronoamperogram obtained at scan rate $0.25 \mathrm{~V}$ in a solution of $0.1 \mathrm{~mol} \mathrm{~L}^{-1} \mathrm{Na}_{2} \mathrm{SO}_{4} / \mathrm{H}_{2} \mathrm{SO}_{4}$ at pH $=3$ for CNT/PAni 1:16 as work electrode for AA determination; (d) analytical curve constructed for AA determination.

good durability and reusability of possible sensors devices based on them.

The analytical curve built for the nanocomposite ratio of 1:16 showed a low limit of detection, equals to $7.91 \mu \mathrm{mol} \mathrm{L} \mathrm{L}^{-1}$. Therefore, CNT/PAni nanocomposites are presented as promising materials for the construction of electrochemical sensors for the detection of L-ascorbic acid, associated with an easy synthetic methodology and no need for further film-processing steps.

\section{Supplementary Information}

Supplementary data are available free of charge at http://jbcs.sbq.org.br as PDF file.

\section{Acknowledgments}

The authors acknowledge the financial support by CNPq, CAPES and National Institute of Science and Technology of Carbon Nanomaterials (INCT Nanocarbon). F. S. L. and E. G. C. N. thank CAPES for the research fellowship.

\section{References}

1. Gajendran, P.; Saraswathi, R.; Pure Appl. Chem. 2008, 80, 2377.

2. Dresselhaus, M. S.; Jorio, A.; Saito, R.; Annu. Rev. Condens. Matter Phys. 2010, 1, 89.

3. Safdari, M.; Al-Haik, M. S.; Carbon 2013, 64, 111.

4. Sahoo, N. G.; Rana, S.; Cho, J. W.; Li, L.; Chan, S. H.; Prog. Polym. Sci. 2010, 35, 837.

5. Barsan, M. M.; Ghica, M. E.; Brett, C. M. A.; Anal. Chim. Acta 2015, 881,1 .

6. Ochiai, L. M.; Agustini, D.; Figueiredo-Filho, L. C. S.; Banks, C. E.; Marcolino-Junior, L. H.; Bergamini, M. F.; Sens. Actuators, B 2017, 241, 978.

7. Caetano, F. R.; Felippe, L. B.; Zarbin, A. J. G.; Bergamini, M. F.; Marcolino-Junior, L. H.; Sens. Actuators, B 2017, 243, 43.

8. Pöhls, J. H.; Johnson, M. B.; White, M. A.; Malik, R.; Ruff, B.; Jayasinghe, C.; Schulz, M. J.; Shanov, V.; Carbon 2012, 50, 4175.

9. Jakubinek, M. B.; White, M. A.; Li, G.; Jayasinghe, C.; Cho, W.; Schulz, M. J.; Shanov, V.; Carbon 2010, 48, 3947.

10. Prasher, R. S.; Hu, X. J.; Chalopin, Y.; Mingo, N.; Lofgreen, K.; Volz, S.; Cleri, F.; Keblinski, P.; Phys. Rev. Lett. 2009, 102, 105901. 
11. Ma, Y.; Cheung, W.; Wei, D.; Bogozi, A.; Chiu, P. L.; Wang, L.; Pontoriero, F.; Mendelsohn, R.; He, H.; ACS Nano 2008, 2, 1197.

12. Salvatierra, R. V.; Cava, C. E.; Roman, L. S.; Zarbin, A. J. G.; Adv. Funct. Mater. 2013, 23, 1490.

13. Oueiny, C.; Berlioz, S.; Perrin, F. X.; Prog. Polym. Sci. 2014, 39, 707.

14. Zengin, H.; Zhou, W.; Jin, J.; Czerw, R.; Smith, D. W.; Echegoyen, L.; Carroll, D. L.; Foulger, S. H.; Ballato, J.; Adv. Mater. 2002, 14, 1480.

15. Bhadra, S.; Khastgir, D.; Singha, N. K.; Lee, J. H.; Prog. Polym. Sci. 2009, 34, 783.

16. Hatchett, D. W.; Josowicz, M.; Janata, J.; J. Phys. Chem. B 2002, 103, 10992.

17. Kuzmany, H.; Sariciftci, N. S.; Neugebauer, H.; Neckel, A.; Phys. Rev. Lett. 1988, 60, 212.

18. MacDiarmid, A. G.; Angew. Chem., Int. Ed. Engl. 2001, 40, 2581.

19. Salvatierra, R. V.; Oliveira, M. M.; Zarbin, A. J. G.; Chem. Mater. 2010, 22, 5222.

20. Salvatierra, R. V.; Moura, L. G.; Oliveira, M. M.; Pimenta, M. A.; Zarbin, A. J. G.; J. Raman Spectrosc. 2012, 43, 1094.

21. Eising, M.; Cava, C. E.; Salvatierra, R. V.; Zarbin, A. J. G.; Roman, L. S.; Sens. Actuators, B 2017, 245, 25.

22. Souza, V. H. R.; Oliveira, M. M.; Zarbin, A. J. G.; J. Power Sources 2014, 260, 34.
23. Mariano, L. C.; Souza, V. H. R.; Kowalski, E. L.; Rocco, M. L. M.; Zarbin, A. J. G.; Koehler, M.; Roman, L. S.; Thin Solid Films 2017, 636, 314.

24. Inagaki, C. S.; Oliveira, M. M.; Bergamini, M. F.; MarcolinoJunior, L. H.; Zarbin, A. J. G.; J. Electroanal. Chem. 2019, 840, 208.

25. Dhara, K.; Debiprosad, R. M.; Anal. Biochem. 2019, 586, 113415.

26. Porto, I. S. A.; Santos Neto, J. H.; dos Santos, L. O.; Gomes, A. A.; Ferreira, S. L. C.; Microchem. J. 2019, 149, 104031.

27. Rana, U.; Paul, N. D.; Mondal, S.; Chakraborty, C.; Malik, S.; Synth. Met. 2014, 192, 43.

28. Ismail, Y. A.; Martínez, J. G.; Otero, T. F.; Electrochim. Acta 2014, 123, 501.

29. Song, J.; Xu, L.; Xing, R.; Li, Q.; Zhou, C.; Liu, D.; Song, H.; Sci. Rep. 2014, 4, 7382.

30. Pakapongpan, S.; Mensing, J. P.; Phokharatkul, D.; Lomas, T.; Tuantranont, A.; Electrochim. Acta 2014, 133, 294.

31. Jurevičiute, I.; Brazdžiuviene, K.; Bernotaite, L.; Šalkus, B.; Malinauskas, A.; Sens. Actuators, B 2005, 107, 716.

32. Yang, Y.; Diao, M. H.; Gao, M. M.; Sun, X. F.; Liu, X. W.; Zhang, G. H.; Qi, Z.; Wang, S. G.; Electrochim. Acta 2014, 132, 496.

33. Tersoff, J.; Appl. Phys. Lett. 1999, 74, 2122.

Submitted: October 3, 2019 Published online: December 18, 2019 